\title{
Mechanical and optical properties of ITO films with anti-reflective and anti-wear coatings
}

\author{
Wen-Fa Wu, Bi-Shiou Chiou * \\ Department of Electronics Engineering and Institute of Electronics, National Chiao Tung University, Hsinchu, Taiwan, ROC
}

Received 7 August 1996; accepted 19 October 1996

\begin{abstract}
In this study, radio frequency (rf) magnetron sputtered ITO films were coated with reactively sputtered $\mathrm{SiO}_{2}$ films. The microhardness, pull-off strength, scratch adhesion strength, optical transmittance and reflectance of the $\mathrm{SiO}_{2} / \mathrm{ITO} / \mathrm{substrate}$ system are investigated. Coating of $\mathrm{SiO}_{2}$ enhances both the hardness and pull-off strength and reduces the scratch critical load of the system. The optical transmittance in the visible range is also improved with the addition of $\mathrm{SiO}_{2}$.
\end{abstract}

\section{Introduction}

Transparent, conductive indium tin oxide (ITO) films exhibit a high electrical conductivity combined with high transmission in the visible spectral range. Hence, ITO has many applications, such as in transparent electrodes, anti-reflection coatings, display devices, and photoelectronic devices [1-3]. However, although the visible transmittance of ITO films is high and the inherent absorption can be very low, a substantial refractive index mismatch exists between the ITO film $(n \approx 2.0)[4-10]$ and air $(n=1)$. This results in significant reflection, particularly in the visible range, and consequently reduces visible transmittance. High visible reflectance may be an impediment to its utilization in some situations. It is therefore clear that a suitable antireflective coating, bringing down the front surface reflectance, can give

\footnotetext{
Corresponding author. Tel.: + 886-35-715507; fax: + 886-35724361.
}

a substantial enhancement of the transmittance. Besides, abrasion of the film occurs during handling and usage, and results in degradation of film properties. Hence, a coating which is both antireflective (AR) and anti-wear is preferable in the application of ITO films.

For a double layer AR coating with ITO as the high refractive index layer deposited on the low-index substrate, the refractive index $n_{\mathrm{A}}$ of the AR layer on the ITO film must satisfy the following condition [11]

$n_{\mathrm{s}}<\frac{n_{\mathrm{A}}^{2}}{n_{\mathrm{air}}} \leq \frac{n_{\mathrm{ITO}}^{2}}{n_{\mathrm{s}}}$

where $n$ is refractive index and the subscripts $\mathrm{s}$ and A stand for the substrate and the AR film, respectively. The substrates employed in this study are polycarbonate (PC) $(n=1.586)$ [11] and corning glass 7059 ( $n=1.523)$. On the basis of Eq. (1), the refractive index of the AR layer should be between 1.259 and 1.588 for PC substrates and between 1.234 and 1.621 for glass substrates. Coating of the sput- 
tered ITO film with an evaporated $\mathrm{MgF}_{2}$ layer has been shown to significantly increase luminous and solar transmittance and reduce luminous reflectance [12]. $\mathrm{MgF}_{2}$ has ideal optical and physical properties for such an application. However, $\mathrm{MgF}_{2}$ films cannot be fabricated with the sputtering process and $\mathrm{rf}$ sputtered $\mathrm{MgF}_{2}$ films show a strong optical absorption due to fluorine loss and magnesium oxidation [11]. Reactively sputtered $\mathrm{SiO}_{2}$ film, with a refractive index of $\sim 1.4$ [13], is a potential candidate for the anti-wear, anti-reflection coating of sputtered ITO films.

In the present study, the mechanical properties, including microhardness, pull-off adhesion, and scratch adhesion of $\mathrm{SiO}_{2}$ coated ITO films are investigated and the optical behavior is evaluated. PC is employed as one of the substrate materials. Because ITO films fabricated on plastics at low substrate temperature without any postdeposition annealing find many applications, such as plastic liquid crystal display devices, flexible electro-optical devices, and unbreakable heat-reflecting mirror. Previous studies suggest that low power radio frequency (rf) magnetron sputtering of ITO on plastics provides highly conductive transparent ITO films $[6,14,15]$. It is believed that the results obtained in this work will be helpful to those seeking to widen the production of sputtered optical film systems.

\section{Experimental details}

ITO and silicon dioxide films were prepared by using a commercial rf magnetron sputtering system (Ion Tech, UK). The sputtering targets were 1 inch hot-pressed oxide ceramic $\left(90 \mathrm{wt} \% \operatorname{In}_{2} \mathrm{O}_{3}\right.$ and 10
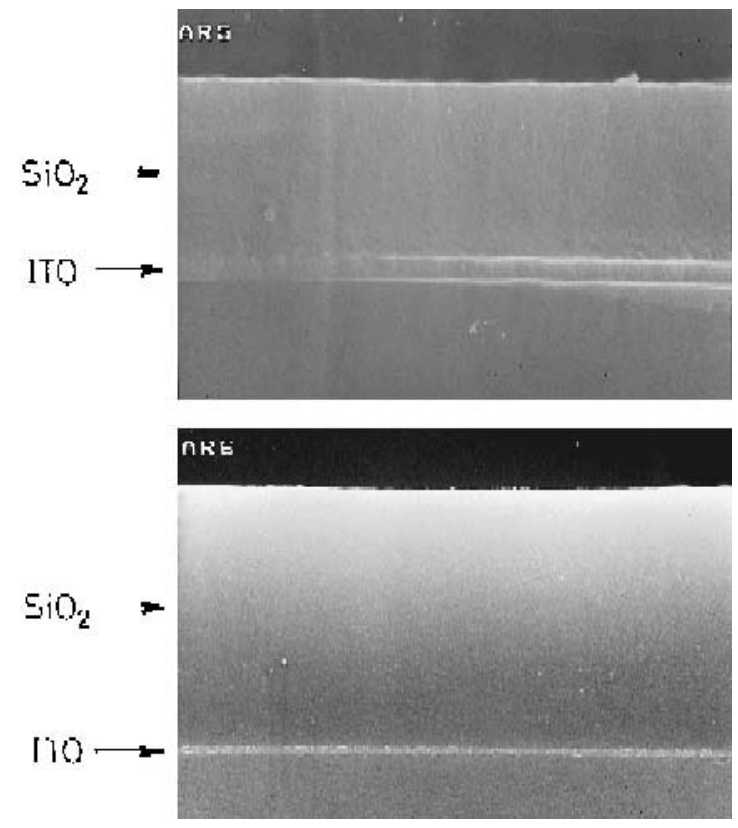

Fig. 1. Cross-sectional SEM micrographs for ITO films with $\mathrm{SiO}_{2}$ coatings. Film thickness (a) ITO: $\sim 1000 \AA, \mathrm{SiO}_{2}: \sim 6000 \AA$, and (b) ITO: $\sim 1000 \AA, \mathrm{SiO}_{2}: \sim 30000 \AA$.

wt $\% \mathrm{SnO}_{2}, 99.99 \%$ purity) and Si ceramic $(99.999 \%$ purity) supplied by Cerac, Inc., USA. The substrates employed were Corning 7059 glass and polycarbonate sheets. Substrates were placed on a holder above the target with a target-to-holder distance of $50 \mathrm{~mm}$ and the holder was rotated at $\sim 10$ rounds / min by a motor to provide good uniformity and prevent polycarbonate from overheating. However, the film deposition rate is reduced because the substrate was rotated off the plasma region periodically. The vacuum chamber was pumped by a diffusion pump. High purity $\mathrm{Ar}(99.999 \%)$ and $\mathrm{O}_{2}(99.5 \%)$ was

Table 1

Mechanical properties of $\mathrm{SiO}_{2} / \mathrm{ITO} /$ substrate system

\begin{tabular}{|c|c|c|c|c|}
\hline \multirow[t]{2}{*}{ Substrate employed } & \multirow{2}{*}{$\begin{array}{l}\text { Microhardness }{ }^{\mathrm{b}}(\mathrm{HK}) \\
\mathrm{PC}\end{array}$} & \multicolumn{2}{|c|}{ Pull-off strength (MPa) } & \multirow{2}{*}{$\begin{array}{l}\text { Scratch critical load (N) } \\
\text { glass }\end{array}$} \\
\hline & & $\overline{\mathrm{PC}}$ & glass & \\
\hline$\sim 1000 \AA$ ITO & $16.5 \pm 0.7$ & 4.97 & $17.86^{\mathrm{a}}$ & $11.7 \pm 1.2$ \\
\hline$\sim 1300 \AA \mathrm{SiO}_{2}+\sim 1000 \AA \mathrm{ITO}$ & $18.5 \pm 1.0$ & - & 79.17 & $9.4 \pm 0.9$ \\
\hline$\sim 6000 \AA \mathrm{SiO}_{2}+\sim 1000 \AA \mathrm{ITO}$ & $84.2 \pm 15.0$ & 6.55 & $27.86^{a}$ & $7.8 \pm 0.8$ \\
\hline$\sim 30000 \AA \mathrm{SiO}_{2}+\sim 1000 \AA \mathrm{ITO}$ & $584.7 \pm 47.7$ & 10.98 & $21.39^{\mathrm{a}}$ & $6.6 \pm 1.6$ \\
\hline
\end{tabular}

a Failure occurred within glass substrates.

${ }^{\mathrm{b}}$ Microhardness of PC substrate is $15.8 \pm 0.3$ [16]. 

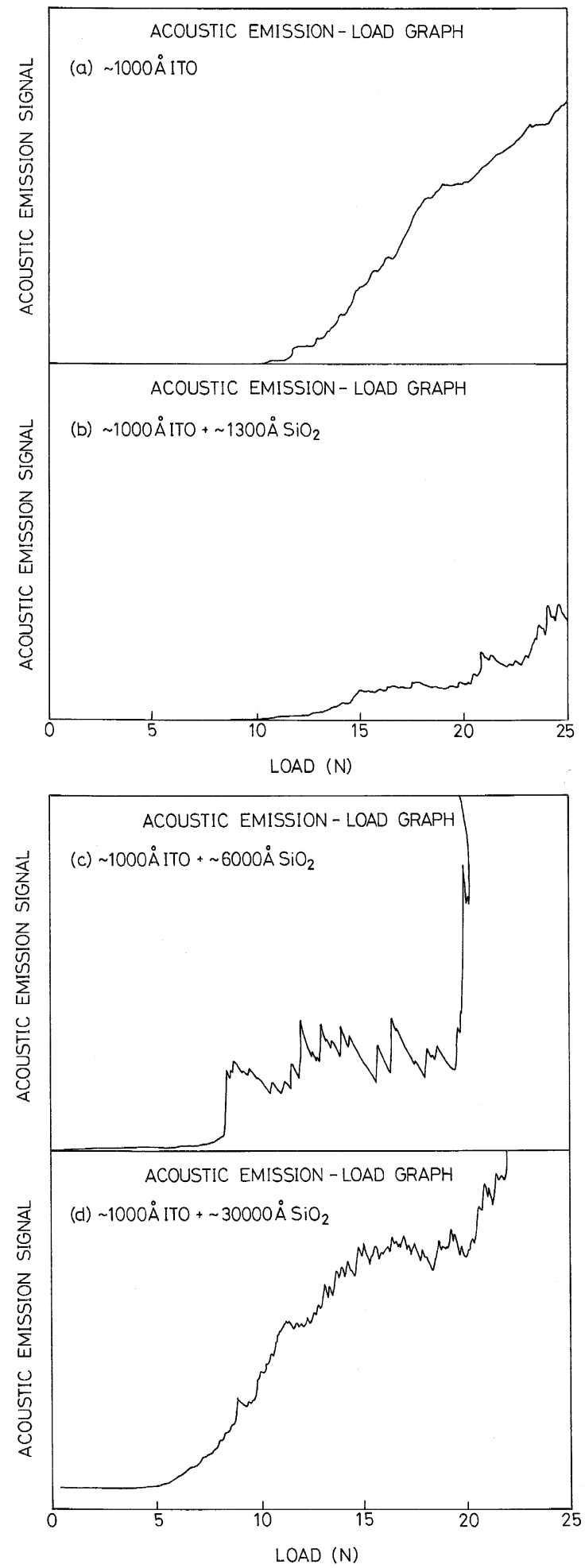

introduced through a mass flow controller after the vacuum chamber was evacuated to about $2.66 \times 10^{-4}$ $\mathrm{Pa}\left(2 \times 10^{-6}\right.$ Torr $)$. Details on the sputtering of ITO and $\mathrm{SiO}_{2}$ films were described elsewhere [4-9,1316 .

The film thickness was measured with a stylus surface profiler. An ellipsometer was used to measure refractive indices for films deposited on $\mathrm{Si}$ wafers. The microstructure of the film was analyzed using a scanning electron microscope (SEM, Hitachi S-4000, Japan). The optical transmittance of the film was measured with an ultra violet-visible-near infrared spectrophotometer (Hitachi U-3410, Japan). The adhesion strength of the coating was measured by an adhesion pull tester and a scratching adhesion tester. In the scratching test a stylus is drawn over the sample surface under a continuously increasing normal force until the coating is detached. The normal force on the indenter causing coating detachment is called the critical load. The coating detachment was observed using acoustic emission detectors to measure high frequency vibrations caused by coating detachment. Critical loads indicated were obtained by averaging the values of three to five different scratches. Detailed morphologies of scratch channels were viewed with an optical microscope. The hardness was measured by Knoop hardness testing technique (MHT-4 ultra-microhardness tester, Austria). The load applied in the hardness measurement was $1 \mathrm{gf}$. Details on the hardness measurement were described elsewhere [14].

\section{Results and discussion}

Fig. 1 gives the cross-sectional SEM micrographs for ITO films with $\mathrm{SiO}_{2}$ coatings. A smooth structure is observed in the $\mathrm{SiO}_{2}$ film, while a columnar structure is obtained in the ITO film.

A hard coating on a soft substrate reduces the wear by preventing ploughing on both the macro and micro scale. Hard coatings are thus particularly useful in abrasive environments. Since $\mathrm{SiO}_{2}$ is harder than ITO is, $\mathrm{SiO}_{2}$ may serve as a wear-resistant

Fig. 2. Acoustic emission curves for ITO films with $\mathrm{SiO}_{2}$ coatings of various thickness. Here the glass substrates are employed. 
coating to prolong the lifetime of ITO films during application. Table 1 summarizes the mechanical properties of $\mathrm{SiO}_{2} / \mathrm{ITO} / \mathrm{PC}$ substrate system. As indicated in Table $1, \mathrm{SiO}_{2}$ coating enhances the microhardness of the ITO/PC substrate considerably. The thicker the $\mathrm{SiO}_{2}$ film, the larger the microhardness. The pull-off strength of the $\mathrm{SiO}_{2} / \mathrm{ITO} /$ substrate system is also improved with the coating of $\mathrm{SiO}_{2}$, especially for samples with glass substrate of which all failures occur within glass substrates. This indicates that the pull-off adhesion of $\mathrm{SiO}_{2} /$ ITO to glass substrate is larger than the strength of the glass substrate.
The scratch test is also employed to study the adhesion of the $\mathrm{SiO}_{2}$-coated ITO film and the substrate. The critical load measured by a scratch technique can be thought of as the adhesion strength of the film on the substrate when films are subjected to wearing and/or abrasion. The scratch critical load shows a decreasing trend with increasing thickness of the $\mathrm{SiO}_{2}$ film. Strain energy stored in the coating may be one of the reasons which cause loss of scratch adhesion strength. The strain energy $u$ stored in the film is given by [17]

$u=\sigma^{2} / 2 E\left(\mathrm{~J} \mathrm{~m}^{-3}\right)$
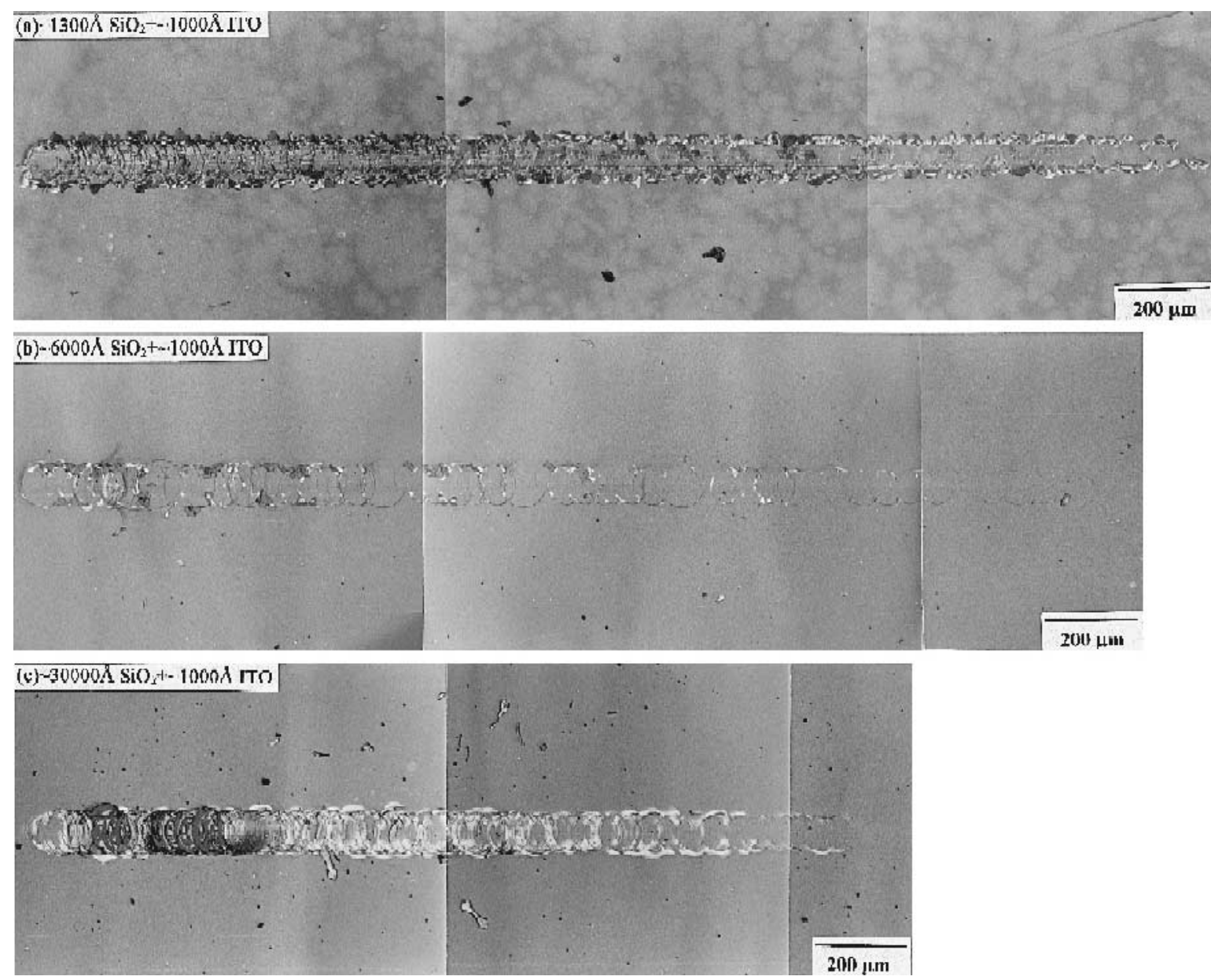

Fig. 3. Optical micrographs of scratch channels for ITO films with $\mathrm{SiO}_{2}$ coatings of various thickness. Here glass substrates are employed. 
The volume energy per unit area on the substrate is thus given by

$u d=\frac{\sigma_{\mathrm{s}}^{2} d_{\mathrm{s}}}{2 E_{\mathrm{s}}}+\frac{\sigma_{\mathrm{I}}^{2} d_{\mathrm{I}}}{2 E_{\mathrm{I}}}\left(\mathrm{J} \mathrm{m}^{-2}\right)$

where $\sigma, E$, and $d$ represent the stress, Young's modulus, and thickness of the film, respectively. The subscripts $\mathrm{s}$ and I stand for $\mathrm{SiO}_{2}$ and ITO, respectively. When the $\mathrm{SiO}_{2}$ film is thicker, the volume energy $u d$ exceeds a critical value at smaller scratch load, exfoliation of the film from the substrate will occur and cracks generated. However, the detailed mechanism which causes the loss of scratch adhesion is subjected to further investigation.
Figs. 2 and 3 illustrate corresponding acoustic emission curves and optical micrographs of scratch channels for $\mathrm{SiO}_{2}$-coated ITO/glass substrate, respectively. Here the load pressed on the indenter tip is continuously increased at the loading rate of 100 $\mathrm{N} / \mathrm{min}$. The indenter is drawn across the surface of the sample with a scanning speed of $10 \mathrm{~mm} / \mathrm{min}$. The load is $25 \mathrm{~N}$ at the end of the scratch channel.

Fig. 4 shows optical micrographs of scratch channels for $\mathrm{SiO}_{2}$ coated ITO on PC substrates. The loading speed and scratching speed are $25 \mathrm{~N} / \mathrm{min}$ and $10 \mathrm{~mm} / \mathrm{min}$, respectively. The load is $5 \mathrm{~N}$ at the end of the scratch channel. For the specimens coated with $\sim 1000 \AA$ ITO and $\sim 1300 \AA \mathrm{SiO}_{2}$, the cracks
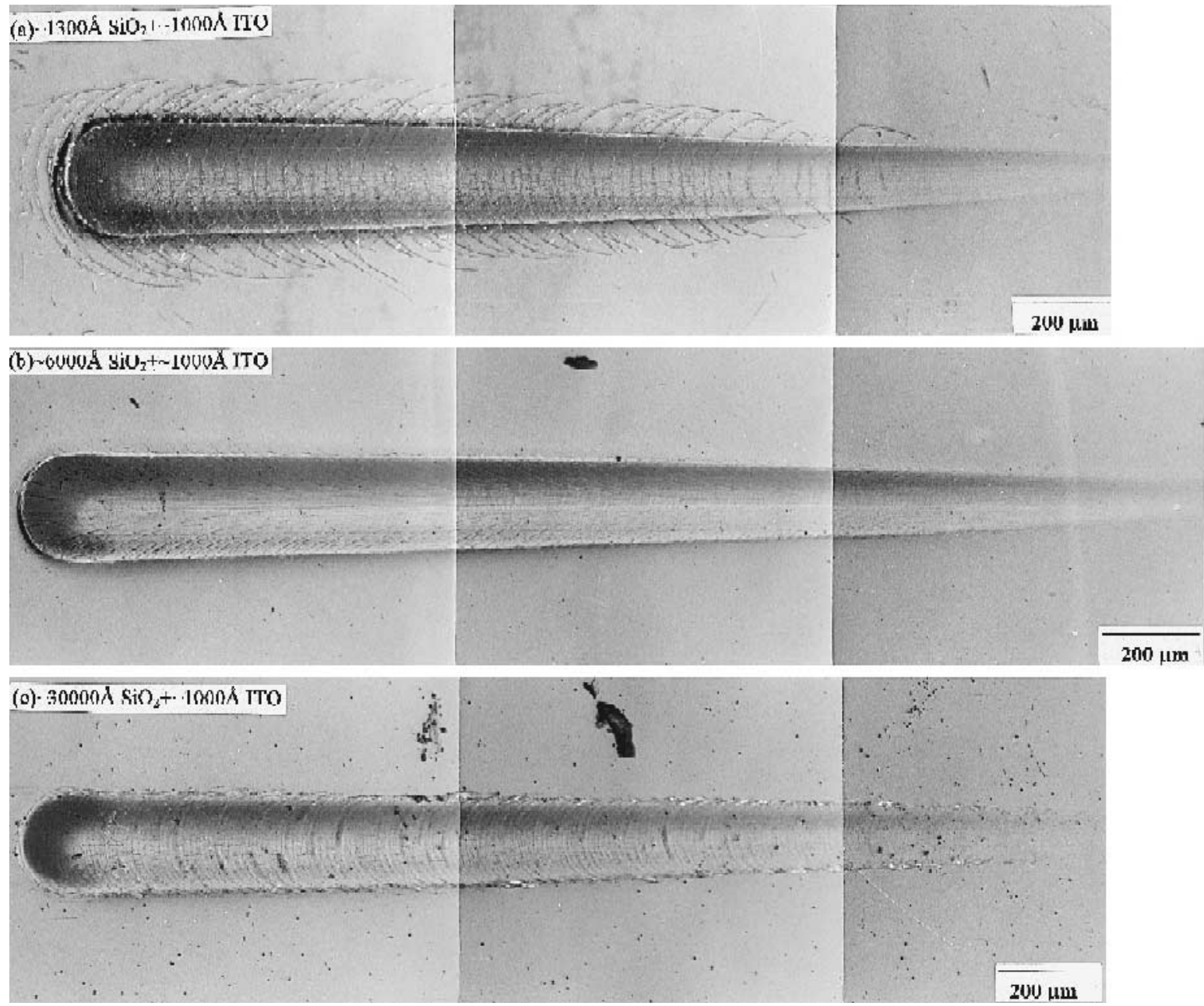

Fig. 4. Optical micrographs of scratch channels for ITO films with $\mathrm{SiO}_{2}$ coating of various thickness. Here PC substrates are employed. 
perpendicular to the scratch channel are observed and cracks are more intense at higher loads. These cracks coincide with the well-known ring cracks due to tensile stresses near the edge of contacts [18]. As mentioned previously, $\mathrm{SiO}_{2}$ coating enhances the microhardness of the ITO/PC substrate considerably. Only few cracks are observed along the scratch channel with increasing thickness of anti-wear $\mathrm{SiO}_{2}$ coating, as shown in Fig. 4(b). However, higher internal stress will exist in the films for thicker films, the semicircular cracks within the scratch channel are observed as the thickness of $\mathrm{SiO}_{2}$ coating increases to $\sim 3 \mu \mathrm{m}$. These cracks form as the indenter deforms the coating and the underlying substrate, resulting in tensile bending moments within the coating as it is pushed down underneath the indenter [18].

Fig. 5 shows the transmittance of a single layer ITO film and ITO film with $\mathrm{SiO}_{2}$ coating. The nominal thicknesses of ITO and $\mathrm{SiO}_{2}$ are $1009 \AA$ and $807 \AA$, respectively. An increase in visible transmittance is observed for ITO with $\mathrm{SiO}_{2}$ film. Coating of $\mathrm{SiO}_{2}$ on ITO does reduce the visible reflection and enhance the transmittance as expected. However, the measured reflectance spectrum deviates from the theoretically calculated one, as exhibited in Fig. 6.

In the design of double-layer AR coatings, two approaches can be employed. One is to select available coating materials with prefixed values of the indices, and calculate the thickness required to give

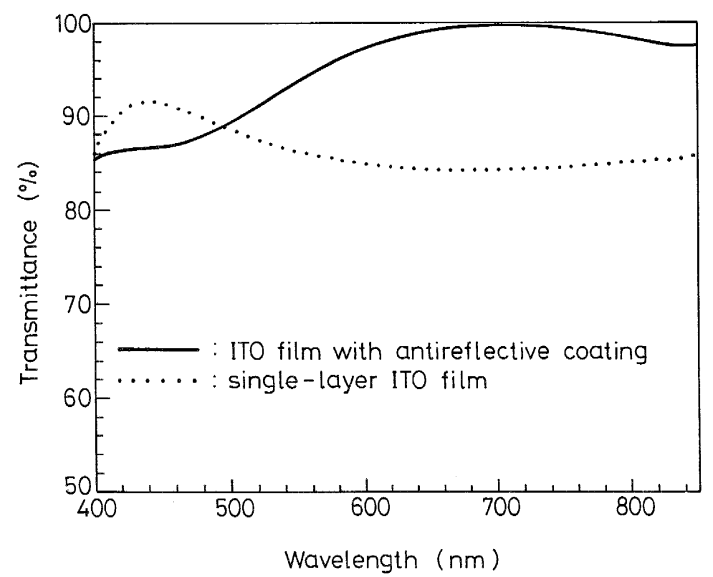

Fig. 5. Transmittance of a single-layer ITO film and ITO film with $\mathrm{SiO}_{2}$ coating. Nominal film thickness: ITO: $1009 \AA$, $\mathrm{SiO}_{2}$ : $807 \AA$

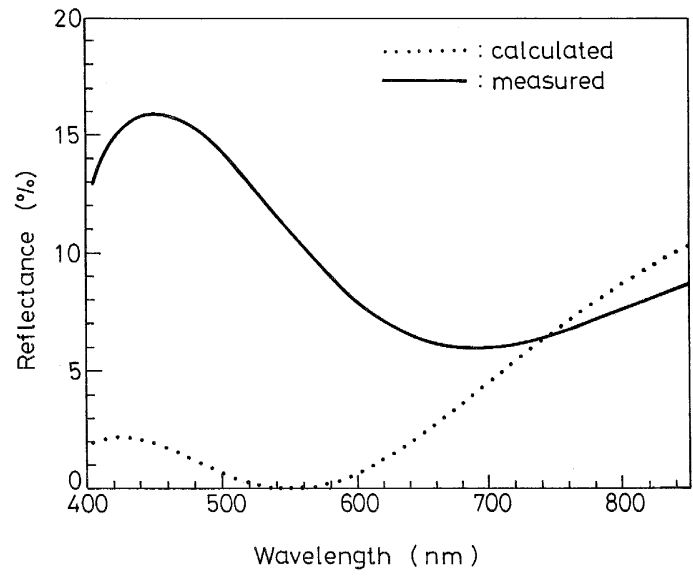

Fig. 6. The calculated and measured reflectance spectra for ITO films with $\mathrm{SiO}_{2}$ coatings. Nominal film thickness: ITO: $1009 \AA$, $\mathrm{SiO}_{2}: 807 \AA$.

zero reflectance [19]. The other approach is to use layers with optical thickness that are integral multiple of $\lambda / 4$ and compute the refractive indices required to give zero reflectance. However, the practical refractive index is not a parameter which can be varied at will. In addition, materials suitable for thin film applications are limited in number and the designer has to use whatever is available. Hence, the first approach is adopted, the refractive indices for ITO and $\mathrm{SiO}_{2}$ were specified and the thickness to achieve zero reflectance calculated.

The difference between experimental data and theoretical derivations is attributed to uncertainties in film thickness and refractive index. In this study, a constant film deposition rate was assumed and film thickness was obtained by controlling the deposition time [7,14]. Errors in the time and deposition rate measurement would lead to deviation between real and nominal film thickness. In addition, a lossless film (i.e., extinction coefficient $k=0$ ) with a constant refractive index $n$ is assumed in the calculation. However, previous investigations indicate that the optical constants $n$ and $k$ of the film would vary with wavelength and other parameters such as film thickness $[4,8]$. However, $\mathrm{SiO}_{2}$ coating on ITO does improve the mechanical hardness, pull-off strength, and the visible transmittance of ITO film. Nevertheless, stringent control on film thickness is needed to further improve the antireflection performance. 


\section{Conclusions}

(1) Coating of $\mathrm{SiO}_{2}$ on ITO film improves both the microhardness and pull-off strength of the film. For the $\mathrm{SiO}_{2} / \mathrm{ITO} / \mathrm{PC}$ substrate system, the microhardness increases from $16.5 \mathrm{HK}$ to $585 \mathrm{HK}$ as the thickness of $\mathrm{SiO}_{2}$ increases from 0 to $\sim 30000 \AA$. For samples with glass substrate, all failures occur within the glass after pull-off test.

(2) The scratch critical load of the $\mathrm{SiO}_{2} / \mathrm{ITO} /$ glass substrate decreases with the increase of $\mathrm{SiO}_{2}$ thickness. Residual strain energy in the $\mathrm{SiO}_{2}$ coating is believed to be one of the reasons which cause loss of scratch adhesion strength.

(3) An increase in the visible transmittance is observed for ITO films with $\mathrm{SiO}_{2}$ coating. The difference between the measured and calculated reflectance spectrum results from errors in film thickness estimation and the assumption of lossless and dispersionless optical constants of the film.

(4) $\mathrm{SiO}_{2}$ is a potential anti-reflective and anti-wear coating material for the transparent, conductive ITO. Coating of ITO with $\mathrm{SiO}_{2}$ improves the mechanical and optical properties of the ITO/substrate system.

\section{Acknowledgements}

This work is supported by the Chung-Shan Institute of Science and Technology (contract No. CS 83-0210-D-009-001) and partly supported by the National Science Council of Taiwan, ROC (contract No. NSC 82-0417-E009-395).

\section{References}

[1] J.C. Manifacier, Thin Solid Films 90 (1982) 297.

[2] K.L. Chopra, S. Major and D.K. Pandya, Thin Solid Films 80 (1981) 143.

[3] F.L. Bouquet and C.R. Maag, IEEE Trans. Nucl. Sci. NS-33 (1986) 1408.

[4] W.F. Wu and B.S. Chiou, Appl. Surf. Sci. 68 (1993) 497.

[5] B.S. Chiou, S.T. Hsieh and W.F. Wu, J. Am. Ceram. Soc. 77 (1994) 1740.

[6] W.F. Wu and B.S. Chiou, Thin Solid Films 247 (1994) 201.

[7] B.S. Chiou, S.T. Hsieh and W.F. Wu, Appl. Surf. Sci. 74 (1994) 297.

[8] W.F. Wu and B.S. Chiou, Semicond. Sci. Technol. 9 (1994) 1242.

[9] W.F. Wu and B.S. Chiou, Semicond. Sci. Technol. 11 (1996) 196.

[10] A.J.P. Theuwissen and G.J. Declerck, Thin Solid Films 121 (1984) 109.

[11] W.F. Wu, Ph.D. Thesis, National Chiao Tung University, Hsinchu, Taiwan (1994).

[12] I. Hamberg, A. Hjortsberg and C.G. Granqvist, Appl. Phys. Lett. 40 (1982) 362

[13] W.F. Wu and B.S. Chiou, Semicond. Sci. Technol. 11 (1996) 1317.

[14] B.S. Chiou and S.T. Hsieh, Thin Solid Films 229 (1993) 146.

[15] W.F. Wu and B.S. Chiou, Thin Solid Films, in press.

[16] W.F. Wu and B.S. Chiou, Thin Solid Films, in press.

[17] A. Kinbara, S. Baba, N. Matuda and K. Takamisawa, Thin Solid Films 84 (1981) 205.

[18] P.J. Burnett and D.S. Rickerby, Thin Solid Film 154 (1987) 403.

[19] K.L. Chopra and I. Kaur, Thin Film Device Applications (Plenum Press, New York and London, 1983). 